\title{
One step back for a leap forward: toward operational measurements of elements at risk
}

\author{
Christian Geiß $^{1}$ (D) Hannes Taubenböck ${ }^{1}$
}

Received: 23 November 2016/ Accepted: 2 January 2017/Published online: 1 March 2017

(C) Springer Science+Business Media Dordrecht 2017

\section{Introduction to the special issue "Geospatial data for multiscale mapping and characterization of elements at risk"}

The impact of extreme geophysical, hydrological, and meteorological events such as earthquakes and tsunamis, floods, storms, or droughts causes both enormous human and monetary losses. The NatCatSERVICE of Munich Re's database on most severe natural catastrophes documents for the years 2004-2015 10,304 loss events with 926,600 fatalities and 1.798 trillion US\$ overall losses worldwide (MunichRE 2016). Prospectively, rapid urbanization observed in regions prone to natural hazards places more people and assets at risk than ever before.

Regarding the assessment of risks, numerous questions can only be answered in a meaningful, consistent, and reliable way when using data which incorporate the spatial domain. In this manner, information about elements at risk needs to be spatially disaggregated and continuous and at the same time up to date and available in a standardized way. This is often not the case for many regions of the world, where suitable data are nonexistent and available at all.

Remote sensing, volunteered geographic information (VGI), and other sources of geospatial data are available at various spatial and temporal scales, and the amount of data is increasing exponentially. These data comprise local to global observations of the earth's surface with a temporal resolution reaching from daily to periodical. The overall aim of this special issue is to present and inform the multidisciplinary risk community on the latest developments, capabilities, and limitations regarding mapping of elements at risk and affiliated characterization on multiple spatial and temporal scales.

This special issue on Geospatial data for multiscale mapping and characterization of elements at risk is closely linked to its precursor special issue in the Natural Hazards

Christian Geiß

christian.geiss@dlr.de

1 German Aerospace Center (DLR), Earth Observation Center (EOC), German Remote Sensing Data Center (DFD), Oberpfaffenhofen, Germany 
Journal on Remote sensing contributing to mapping earthquake vulnerability and effects (Taubenböck and Strunz 2013). Regarding the risk component(s) addressed, this special issue has a narrower focus, dealing primarily with mapping and characterization of the exposed elements. At the same time, the special issue clearly widens the utility for riskrelated analysis and applications by showing concepts, data, methods, results, and applications, regarding elements at risk, which are largely hazard-independent. This concept is intended to address a very broad scope of researchers and stakeholders.

\section{Notes on the evolvement of the role of remote sensing within natural hazard risk assessment}

In general, availability of geospatial data for the analysis and assessment of risks triggered by natural hazards is constantly increasing. Digital geospatial data originate from remote sensing, commercial or administrative databases, geotagged data from social networks, mobile devices, among many others. In this section, we give a brief overview on the evolvement of the role of remote sensing, the primary data source used and discussed in this special issue, within natural hazard risk assessment. Therefore, we exemplarily focus on earthquakes, which is the hazard that is dominantly considered in the research papers of the special issue.

\subsection{First phase: Hazard-focused analysis}

The deployment of remote sensing for earthquake hazard research can be tracked back to the first appearance of commercially available satellite images in the 1970s. Those data were used to map active faults and structures (Tronin 2006). Subsequent scientific contributions focused on the understanding and documentation of location, slip rates as well as the kinematics and dynamics of active faults on interseismic temporal scales, among others. A wide spectrum of air and spaceborne remote sensing reaching from optical sensors to radar systems was used for this purpose (Tralli et al. 2005; Geiß and Taubenböck 2013). In particular, differential interferometric synthetic aperture radar data proved useful in mapping and quantifying pre-seismic land-surface deformations in the amount of centimeters (Stramondo et al. 2007; Bayuaji et al. 2010).

\subsection{Second phase: Integrative yet explorative studies on the capabilities of remote sensing for assessment of exposure and vulnerability}

The use of remote sensing for assessment of earthquake exposure and vulnerability is a less long-established field compared to earthquake hazard research. This corresponds to a changing perspective of the scientific community which increasingly considers the assessment of vulnerability and its constituent aspects as a pivotal part of a risk analysis (Pelling 2003; Turner et al. 2003). Therefore, the availability of new sensor systemsdelivering very high spatial resolution imagery-enabled an appreciable share of remote sensing first (Geiß and Taubenböck 2013). Notably, related studies aimed at an integrative view and considered numerous parameters for a holistic characterization and assessment of vulnerability (e.g., Taubenböck et al. 2008; Ebert et al. 2009; Prasad et al. 2009; Taubenböck et al. 2009a; Zeng et al. 2012). Therefore, the derivation of a wide variety of vulnerability-related parameters from remote sensing comprising for example population 
(e.g., Dobson et al. 2000; Taubenböck et al. 2007; Chen 2002; Aubrecht et al. 2012), and properties of the built environment (e.g., Mueller et al. 2006; French and Muthukumar 2006; Sahar et al. 2010), among others, was explored.

\subsection{Third phase: Methodological elaboration of specific aspects of exposure and vulnerability}

With a slight temporal offset to this exploratory phase, numerous studies focused on specific aspects of risk assessment procedures and aimed to provide a deeper understanding of various details and parameters. Given the nature of remote sensing as tool for providing physical measurements of the earth's surface, especially the physical vulnerability of built environments was subject to an increasing scientific contemplation in the last decade. Since pioneering works of, e.g., Sarabandi and Kiremidjian (2007), who estimate the seismic structural type of buildings based on remote sensing and ancillary information for deployment in earthquake loss estimation models, numerous studies were conducted and different approaches postulated. For instance, Taubenböck et al. (2009b), Borzi et al. (2011), Polli and Dell' Acqua (2011), and Su et al. (2015) characterize the built environment with remote sensing data and retrieve specific fragility functions or damage probability matrices, respectively, for designated building types. In contrast to that, e.g., Borfecchia et al. (2010), and Geiß et al. (2014, 2015) combine limited in situ ground truth building inventory data with features from remote sensing and use techniques of statistical inference for a complete labelling of the residual building inventory according to relevant vulnerability levels. Similar methodological principles were exploited by Wieland et al. (2012), Pittore and Wieland (2013), and Geiß et al. (2016) to assess seismic vulnerability on an aggregated spatial level to allow for covering larger areas.

\section{One step back for a leap forward: toward operational measurements of elements at risk}

As can be seen from the previous section, a large share of research focused on the development of techniques for mapping and characterization of elements at risk and assessing vulnerability, which are capable of providing a high level of thematic detail (i.e., aiming to provide detailed thematic information by incorporation of sufficient prior knowledge and corresponding to a holistic understanding of vulnerability). At the same time, data requirements, which incorporate, e.g., very high spatial resolution remote sensing imagery and detailed in situ data, hamper utilization capabilities of many approaches due to availability, monetary costs, and processing requirements. Moreover, local idiosyncrasies must not be bypassed and transfer of models can hardly be carried out in a non-adaptive manner.

In general, exposure can be considered as a highly tangible component of risk in contrast to the fuzzy concept of vulnerability, since it comprises assets potentially affected by a hazardous event such as people, properties, infrastructure, or economic activities (Schneiderbauer and Ehrlich 2004; Geiß and Taubenböck 2013). However, timely mapping and characterizing of those assets in a spatially continuous and detailed way for large areas remains a major challenge. In this manner, this special issue follows the governing idea to establish exposure information on various spatial and temporal scales. At the first glance, this may seem as a step back since previous works could already generate detailed 
exposure and in particular vulnerability information. Yet, as mentioned, those approaches suffered dominantly from small-area coverage, high data costs, considerable in situ data collection efforts, and large processing requirements. As such, this special issue is intended as a first step toward exposure estimation approaches allowing for large-area coverage, keeping a high spatial detail and internalizing capabilities for frequent updating and monitoring. Such approaches and resulting data sets can be a leap toward significantly improved global risk models.

In this manner, this special issue contains a considerable variety of works. Pittore et al. present conceptual considerations and a road map for a global dynamic exposure database. Acevedo et al. present an exposure model for the residential building stock in Antioquia and affiliated vulnerability properties for seismic risk assessment. They rely on both cadastral information and survey data. Santa María et al. present an exposure model on a national level for Chile based on statistical data and refined regional models incorporating remote digital surveys and remote sensing imagery. Keeping the geographic scope in Chile, Geiß et al. jointly use remote sensing imagery and VGI for estimation of crucial exposure components for the city of Valparaíso with a high level of automatization. Also Qi et al. rely on various data sources comprising remote sensing imagery, in situ imagery, and crowdsourcing data for mapping of exposure and seismic vulnerability of buildings in the city of Tangshan in China. More focused on the actual application, Wyss shows earthquake loss estimations regarding the Gorkha M7.8 earthquake of April 25, 2015, which are based on a global exposure data set. Likely application-oriented, Fekete et al. combine VGI with other geospatial data to focus on spatial exposure in the context of flood and blackout for the city of Cologne, Germany. The special issue is closed by a comments section. There, authors from science, intergovernmental organizations, and the commercial sector give lively examples of past experiences, current best practices, and exigent future challenges and needs.

The special issue is a plea for methodological progress and the operationalized development of global (or at least large area) exposure information using multi-source geospatial data. Connected to this is the plea for multidisciplinary thinking, as well as openness for sharing data and algorithms between different science communities. As we have seen in the past, an open dialogue always triggered a significant leap forward regarding conceptual issues, methodological developments, operational data generation, and perception of risk. Such a development appears exigent in times of for instance climate change and global urbanization process, which define unprecedented challenges for our society and environments.

\section{References}

Aubrecht C, Özceylan D, Steinnocher K, Freire S (2012) Multi-level geospatial modeling of human exposure patterns and vulnerability indicators. Nat Hazards 68:147-163

Bayuaji L, Sumantyo JTS, Kuze H (2010) ALOS PALSAR D-InSAR for land subsidence mapping in Jakarta, Indonesia. Can J Remote Sens 36:1-8

Borfecchia F, Pollino M, De Cecco L, Lugari A, Martini S, La Porta L, Ristoratore E, Pascale C (2010) Active and passive remote sensing for supporting the evaluation of the urban seismic vulnerability. Ital J Remote Sens 42(3):129-141

Borzi B, Dell'Acqua F, Faravelli M, Gamba P, Lisini G, Onida M, Polli D (2011) Vulnerability study on a large industrial area using satellite remotely sensed images. Bull Earthq Eng 9:675-690

Chen K (2002) An approach to linking remotely sensed data and areal census data. Int J Remote Sens 23:37-48 
Dobson JE, Bright EA, Coleman PR, Durfee RC, Worley BA (2000) LandScan: a global population database for estimating populations at risk. Photogramm Eng Remote Sens 66:849-857

Ebert A, Kerle N, Stein A (2009) Urban social vulnerability assessment with physical proxies and spatial metrics derived from air- and spaceborne imagery and GIS data. Nat Hazards 48:275-294

French SP, Muthukumar S (2006) Advanced technologies for earthquake risk inventories. J Earthq Eng 10(2):207-236

Geiß C, Taubenböck H (2013) Remote sensing contributing to assess earthquake risk: from a literature review towards a roadmap. Nat Hazards 68:7-48

Geiß C, Taubenböck H, Tyagunov S, Tisch A, Post J, Lakes T (2014) Assessment of seismic building vulnerability from space. Earthq Spectra 30(4):1553-1583

Geiß C, Aravena Pelizari P, Marconcini M, Sengara W, Edwards M, Lakes T, Taubenböck H (2015) Estimation of seismic buildings structural types using multi-sensor remote sensing and machine learning techniques. ISPRS J Photogramm Remote Sens 104:175-188

Geiß C, Jilge M, Lakes T, Taubenböck H (2016) Estimation of seismic vulnerability levels of urban structures with multisensor remote sensing. IEEE J Sel Top Appl Earth Obs Remote Sens 9(5):1913-1936

Mueller M, Segl K, Heiden U, Kaufmann H (2006) Potential of high-resolution satellite data in the context of vulnerability of buildings. Nat Hazards 38:247-258

Munich RE (2016) Annual statistics. https://www.munichre.com/touch/naturalhazards/en/natcatservice/ annual-statistics/index.html. Last accessed 9 Nov 2016

Pelling M (2003) The vulnerability of cities-natural disasters and social resilience. Earthscan, London

Pittore M, Wieland M (2013) Towards a rapid probabilistic seismic vulnerability assessment using satellite and ground-based remote sensing. Nat Hazards 68:115-145

Polli D, Dell' Acqua F (2011) Fusion of optical and SAR data for seismic vulnerability mapping of buildings. In: Prasad S, Bruce LM, Chanussot J (eds) Optical remote sensing. Advances in signal processing and exploitation techniques. Springer, Heidelberg, pp 329-341

Prasad JSR, Singh Y, Kaynia AM, Lindholm C (2009) Socioeconomic clustering in seismic risk assessment of urban housing stock. Earthq Spectra 25:619-641

Sahar L, Muthukumar S, French P (2010) Using aerial imagery and GIS in automated building footprint extraction and shape recognition for earthquake risk assessment of urban inventories. IEEE Trans Geosci Remote Sens 48(9):3511-3520

Sarabandi P, Kiremidjian A (2007) Development of algorithms or building inventory compilation through remote sensing and statistical inferencing. The John A. Blume Earthquake Engineering Center, Department of Civil and Environmental Engineering, Stanford University, Stanford, CA, USA, Report No. 158

Schneiderbauer S, Ehrlich D (2004) Risk, hazard and people's vulnerability to natural hazards. A review of definitions, concepts and data. Joint Research Centre, European Commission, EUR 21410

Stramondo S, Saroli M, Tolomei C, Moro M, Doumaz F, Pesci A, Loddo F, Baldi P, Boschi E (2007) Surface movements in Bologna (Po Plain-Italy) detected by multitemporal DInSAR. Remote Sens Environ 110:304-316

Su GW, Qi WH, Zhang SL, Sim T, Liu XS, Sun R, Sun L, Jin YF (2015) An integrated method combining remote sensing data and local knowledge for the large-scale estimation of seismic loss risks to buildings in the context of rapid socioeconomic growth: a case study in Tangshan, China. Remote Sens 7:2543-2601. doi:10.3390/rs70302543

Taubenböck H, Strunz G (2013) Widening a narrow road: remote sensing contributing to the multifaceted problem of earthquake risk reduction. Nat Hazards 68:1-5

Taubenböck H, Roth A, Dech S (2007) Linking structural urban characteristics derived from high resolution satellite data to population distribution. In: Coors V, Rumor M, Fendel E, Zlatanova S (eds) Urban and regional data management. Taylor \& Francis, London, pp 35-45

Taubenböck H, Post J, Roth A, Zosseder K, Strunz G, Dech S (2008) A conceptual vulnerability and risk framework as outline to identify capabilities of remote sensing. Nat Hazards Earth Syst Sci 8:409-420

Taubenböck H, Goseberg N, Setiadi N, Lämmel G, Moder F, Oczipka M, Klüpfel H, Wahl R, Schlurmann T, Strunz G, Birkmann J, Nagel K, Siegert F, Lehmann F, Dech S, Gress A, Klein R (2009a) "LastMile" preparation for a potential disaster-interdisciplinary approach towards tsunami early warning and an evacuation information system for the coastal city of Padang, Indonesia. Nat Hazards Earth Syst Sci 9:1509-1528

Taubenböck H, Roth A, Dech S, Mehl H, Münich JC, Stempniewski L, Zschau J (2009b) Assessing building vulnerability using synergistically remote sensing and civil engineering. In: Kreck A, Rumor M, Zlatanova S, Fendel E (eds) Urban and regional data management. Taylor \& Francis, London, pp 287-300 
Tralli DM, Blom RG, Zlotnicki V, Donnellan A, Evans DE (2005) Satellite remote sensing of earthquake, volcano, flood, landslide and coastal inundation hazards. ISPRS J Photogramm Remote Sens 59:185-198

Tronin AA (2006) Remote sensing and earthquakes: a review. Phys Chem Earth 31:138-142

Turner BL, Kasperson R, Matson P, McCarthy J, Corell R, Christensen L, Eckley N, Kasperson J, Luers A, Martello M, Polsky C, Pulsipher A, Schiller A (2003) A framework for vulnerability analysis in sustainability science. Proc Natl Academy Sci U. S. A 100(14):8074-8079

Wieland M, Pittore M, Parolai S, Zschau J, Moldobekov B, Begaliev U (2012) Estimating building inventory for rapid seismic vulnerability assessment: towards an integrated approach based on multisource imaging. Soil Dyn Earthq Eng 36:70-83

Zeng J, Zhu ZY, Zhang JL, Ouyang TP, Qiu SF, Zou Y, Zeng T (2012) Social vulnerability assessment of natural hazards on county-scale using high spatial resolution satellite imagery: a case study in the Luogang district of Guangzhou, South China. Environ Earth Sci 65:173-182 